\title{
A New 193 nm Single Layer Resist Based on Cycloolefin Maleic Anhydride Polymers
}

\author{
Si-Hyeung Lee, Ki-Young Kwon, Dong-Won Jung, Sook Lee, Kwang-Sub Yoon, \\ Hyun-Woo Kim, Sang-Jun Choi, Sang-Gyun Woo, and Joo-Tae Moon
}

\author{
Process Development Team, Semiconductor R\&D Center, Samsung Electronics Co., Ltd. \\ San \#24, Nongseo-Ri, Kiheung-Eup, Yongin-Si, Kyungki-Do, Korea \\ Bluelsh@samsung.co.kr
}

\begin{abstract}
A series of new cycloaliphatic olefin monomers protected by alicyclic hydrocarbon groups were synthesized. New cycloolefin-maleic anhydride (COMA) polymers were also designed and prepared using the new monomers for $193 \mathrm{~nm}$ resist applications. These polymer were synthesized by free radical polymerization method, utilizing azobisisobutyronitrile (AIBN). The new COMA polymer had good transparency at $193 \mathrm{~nm}$ and had an etch rate in $\mathrm{CF}_{4}$ mixture plasma of approximate 1.0 times that of $\mathrm{KrF}$ resists. Using $\mathrm{ArF}$ exposure tools $(\mathrm{NA}=0.6, \sigma=0.7$ ), $130 \mathrm{~nm} \mathrm{~L} / \mathrm{S}$ patterns were resolved. When exposed with off-axis illumination, $100 \mathrm{~nm} \mathrm{~L} / \mathrm{S}$ patterns were resolved.
\end{abstract}

Keywords: Photoresist, chemically amplified resist, ArF lithography, COMA

\section{Introduction}

The ArF lithography using chemically amplified resists has been investigated as one of the most promising technologies for producing patterns below $0.15 \mu \mathrm{m}^{1-8}$. However, in considering resins for use as matrix polymers in $193 \mathrm{~nm}$ photoresist applications, factors such as sensitivity, transparency to $193 \mathrm{~nm}$ radiation, adhesion to substrate, dry etch resistance, ease of synthesis, and availability of monomers are very critical $^{1,2}$. The use of polymers of acrylic and methacrylic esters has provided a good imaging performance at $193 \mathrm{~nm}$. But the polymers have insufficient dryetch resistance to fluorine-based gas chemistries. Because sub-130 nm process needs the resist thickness less than $3000 \AA$ in view of the aspect ratio, ArF single layer resist must have superior dry etch resistance to that of $\mathrm{KrF}$ resist. Previously we reported a cycloolefin-maleic anhydride alternating systems that showed good lithographic performances ${ }^{7,8}$. However, the resists showed an insufficient dry etch resistance and poor shelf life stability due to hydrolysis of maleic anhydride moiety by hydroxy group in the resins.

In this paper, we propose a series of dry etch resistant polymers of cycloaliphatic olefins and cycloolefin-maleic anhydride systems having alicyclic protecting groups for $193 \mathrm{~nm}$ resist applications.

\section{Experiments}

\subsection{Materials}

All chemicals were purchased from Aldrich Chemical Company and used as received with the following exceptions. Cyclopentadiene was obtained by cracking dicyclopentadiene and used immediately. The onium salt, triphenylsulfonium triflate (TPS-105) was used as a photo acid generator (PAG). 2,2'-Azobisisobutyronitrile (AIBN) which was purchased from TCI Co. was recrystallized in ethanol.

\subsection{Synthesis of monomers}

The synthetic scheme of monomers is shown in Figure 1.

Alicyclic hydrocarbon group protected norbornene carboxylate (ALCNC):

Alicyclic alcohols were synthesized from alicyclic ketones with ethyl magnesium bromide by the Grignard reaction. Acrylates protected by alicyclic hydrocarbon (ALC) groups were synthesized by conventional esterification method between acryloyl chloride and the alicyclic alcohols in the presence of triethyl amine.

Freshly cracked cyclopentadiene (CPD) $(66 \mathrm{~g}, 1.0$ mol) was added to a stirred solution of the acrylates $(1 \mathrm{~mol})$ at $0^{\circ} \mathrm{C}$. After the mixture was stirred for $8-10 \mathrm{hr}$ at $50^{\circ} \mathrm{C}$, the product was isolated by vacuum distillation as colorless oil. The monomers were named as MALCNC and EALCNC according to the $\mathrm{R}$ groups in Figure 1.

Received March 31, 2000

Accepted May 17, 2000 


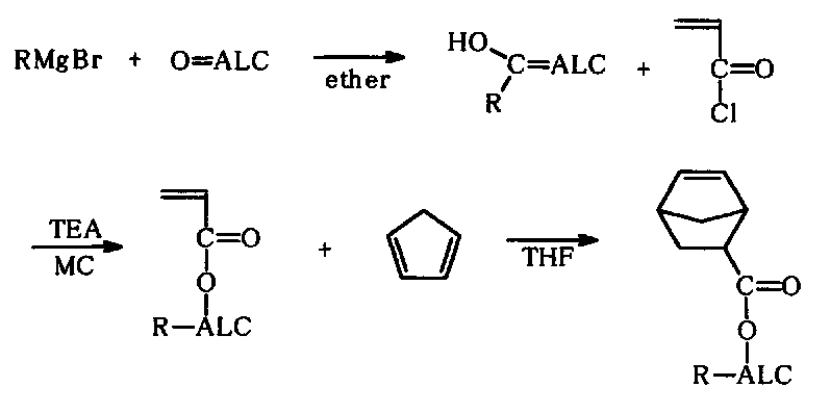

$\mathrm{R}=\mathrm{CH}_{3}, \mathrm{CH}_{3} \mathrm{CH}_{2}$
(A) MALCNC $\left(\mathrm{R}=\mathrm{CH}_{3}\right)$, EALCNC $\left(\mathrm{R}=\mathrm{CH}_{2} \mathrm{CH}_{3}\right)$

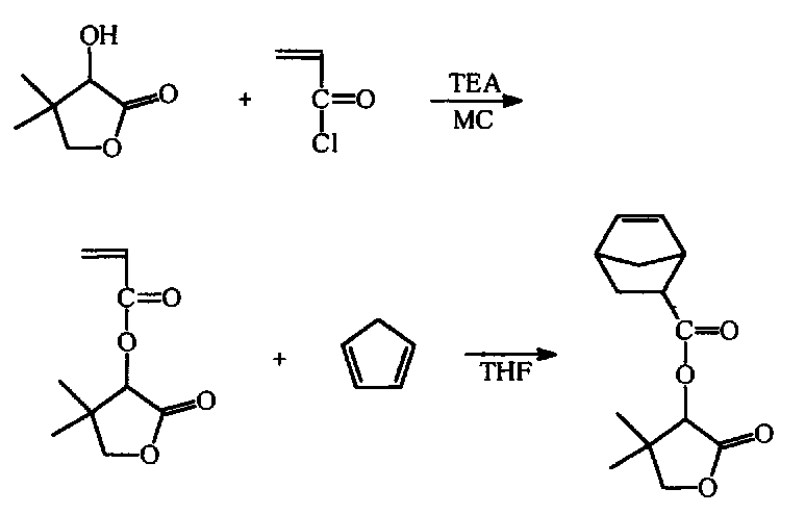

(B) PLNC

Figure 1. Synthethic scheme of (A) MALCNC and EALCNC (B) PTLNC

Pantolactone norbornene carboxylate (PTLNC): Pantolactone acrylate (PTLA) was prepared from acryloyl chloride and pantolactone. Freshly cracked CPD (66g, $1.0 \mathrm{~mol})$ was added to a stirred solution of PLA $(184 \mathrm{~g}, 1 \mathrm{~mol})$ at $0^{\circ} \mathrm{C}$. The mixture was stirred for $8-10 \mathrm{hr}$ at $50^{\circ} \mathrm{C}$, and the product was isolated by vacuum distillation as white crystallines.

\subsection{Synthesis of polymers}

Poly(MALCNC-MA), Poly(EALCNC-MA), and Poly(MALCNC-MA-PLNC) were prepared with AIBN in ethyl acetate at $65^{\circ} \mathrm{C}$. The solution was diluted and precipitated in isopropyl alcohol(IPA) and $n$-hexane. The chemical structures of the polymers were shown in Figure 2.

\subsection{Lithographic evaluations}

Polymers were dissolved in PGMEA. The solutions were filtered through a $0.2 \mu \mathrm{m}$ Millipore filter, and spin-coated at $2500-3000 \mathrm{rpm}$ to obtain about 0.5-1 $\mu \mathrm{m}$-thick films on quartz cells for UV spectroscopy. Resist solutions were prepared by dissolving each matrix polymers $(\sim 10 \mathrm{wt} \%$ for

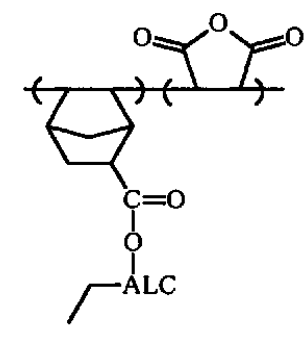

(A)

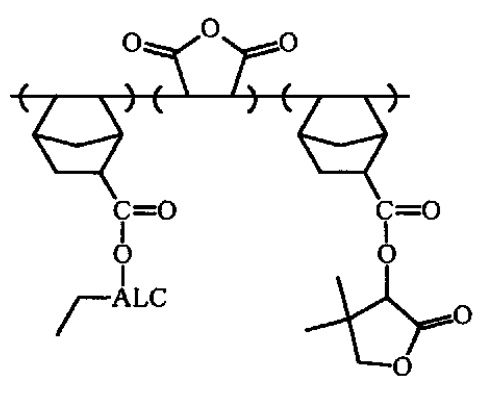

(B)

Figure 2. Chemical structure of the polymers (A) Poly (EALCNC-MA) (B) poly(EALCNC -MA-PTLNC)

solution) in PGMEA. TPS-105 was added to the solutions as a PAG. AR-20 (Shipley) was used as a BARC. Imaging experiments were done by ISI ArF exposure tool $(\mathrm{NA}=0.6)$. After $\mathrm{PEB}$ was done at appropriate temperature, $L / S$ patterns were resolved by developing for $60 \mathrm{sec}$ with $2.38 \mathrm{wt} \%$ tetramethylammonium hydroxide (TMAH) solution. For measuring selectivity and post-etch profile, $\mathrm{L} / \mathrm{S}$ patterns were formed on $5000 \AA$-thick P-TEOS (tetraethylorthosilicate) and etched for 60 sec under oxide etch condition; $150 \mathrm{mT}$ pressure, $700 \mathrm{~W}$ power, $300 \mathrm{sccm} \mathrm{Ar}, 10 \mathrm{sccm} \mathrm{CF}_{4}$, and 10 sccm $\mathrm{CHF}_{3}$.

\section{Results and Discussion}

3.1 Preparation of matrix polymers

The polymerization results of EALCNC, MA and PTLNC were shown in Table 1. The polymers were prepared in good yield, and had appropriate molecular weights. The molecular weights of the polymers were also controllable. The weight average molecular weights of the poly(EALCNCMA-PLNC) were in the range of 15,500-19,200 and the polydispersities were $1.76-1.90$ in $63-65 \%$ conversion. The polymers had sufficient transmittance at $193 \mathrm{~nm}$. The optimum feed ratio was determined by evaluation of the resists based on the polymers in Table 1. 
Table 1. Radical polymerization a of EALCNC-MA-PTLNC

\begin{tabular}{ccccc}
\hline Polymer & $\mathrm{M}_{\mathrm{w}}$ & $\mathrm{M}_{\mathrm{w}} / \mathrm{M}_{\mathrm{n}}$ & $\begin{array}{c}\text { Transmittance } \\
(\% / 0.5 \mu \mathrm{m})\end{array}$ & $\begin{array}{c}\text { Yield } \\
(\%)\end{array}$ \\
\hline SAS3.3-01 & 15,500 & 1.85 & 64.0 & 63 \\
SAS3.3-03 & 16,200 & 1.86 & 63.8 & 63 \\
SAS3.3-06 & 17,200 & 1.76 & 67.6 & 66 \\
SAS3.3-08 & 19,200 & 1.90 & 63.5 & 65 \\
SAS3.3-09 & 18,100 & 1.90 & 63.1 & 63 \\
\hline
\end{tabular}

'The polymers were prepared by varying the monomer ratios in feeding.

3.2 Deprotection and imaging experiment

Before imaging experiments, the acid catalyzed cleavages of the copolymers, poly(MALCNCMA) and poly(EALCNC-MA) were studied using TGA. The TGA thermograms of the copolymers

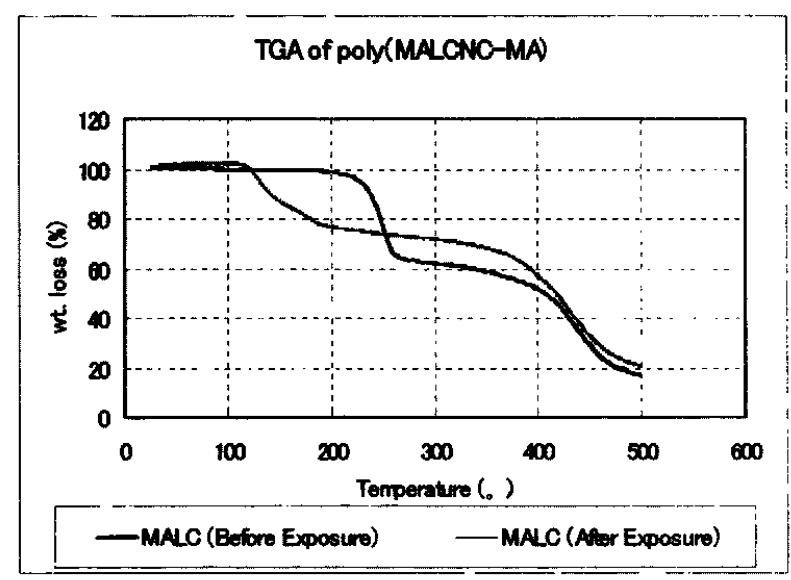

(A)

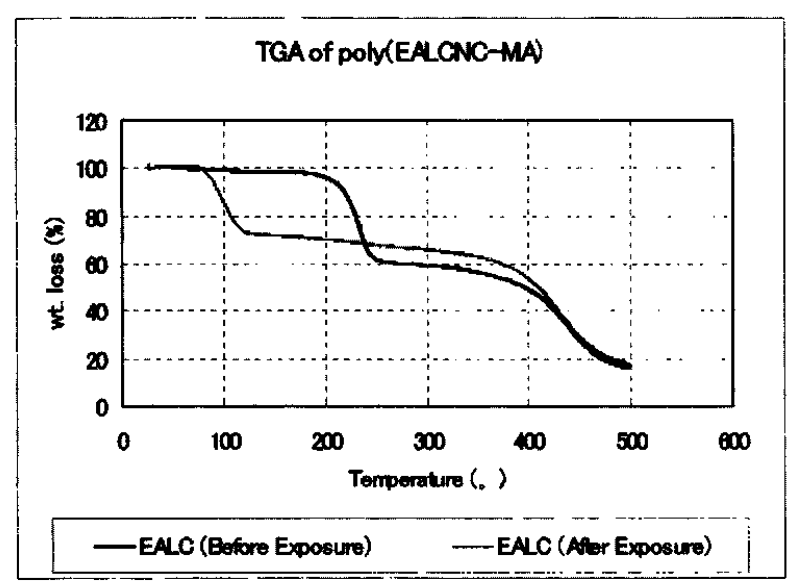

(B)

Figure 3. TGA thermograms of (A) poly(MALCNC -MA) and (B) poly(EALCNC-MA) were shown in Figure 3. In the absence of acids, deprotections of both MALC groups and EALC groups occurred above $190^{\circ} \mathrm{C}$, whereas in the presence of the photo-generated acids, cleavages of the MALC groups and EALC groups were found to begin at $\sim 120^{\circ} \mathrm{C}$ and $\sim 80^{\circ} \mathrm{C}$, respectively. By comparing curves (A) and (B) in Figure 3, we can find that EALC groups are deprotected more rapidly than MALC groups. And we can also expect that the deprotection reaction of EALC groups is more sensitive than that of MALC groups. Above results were confirmed by the evaluations of the resists based on poly(EALCNCMA) and poly (MALCNC-MA).

In Figure 4, we can see that the thermal deprotection of the EALC groups resulted in almost the same weight loss as the calculated weight loss of poly(EALCNC-MA-PLNC). So it is verified that the polymer composition is determined by the feed ratio of the monomers.

\subsection{Lithographic performance}

Figure 5 shows the L/S patterns of the resists based on the copolymers, poly (MALCNC-MA) and poly(EALCNC-MA). The optimum PEB temperature of the poly(EALCNC-MA) was lower than that of poly(MALCNC-MA) as expected. The resolution of poly(EALCNC-MA) was better than that of poly(MALCNC-MA), but $130 \mathrm{~nm} \mathrm{~L} / \mathrm{S}$ pattern was not resolved. So PLNC was introduced to increase adhesion and dissolution contrast of the resist. Figure 6 shows the L/S patterns of the resist based on the terpolymer, poly(EALCNC-MA-PLNC). Using conventional illumination, $130 \mathrm{~nm} \mathrm{~L} / \mathrm{S}$ patterns without T-top were resolved. When exposed with off-axis illumination, $100 \mathrm{~nm} \mathrm{~L} / \mathrm{S}$ patterns were resolved as shown in Figure 7. 


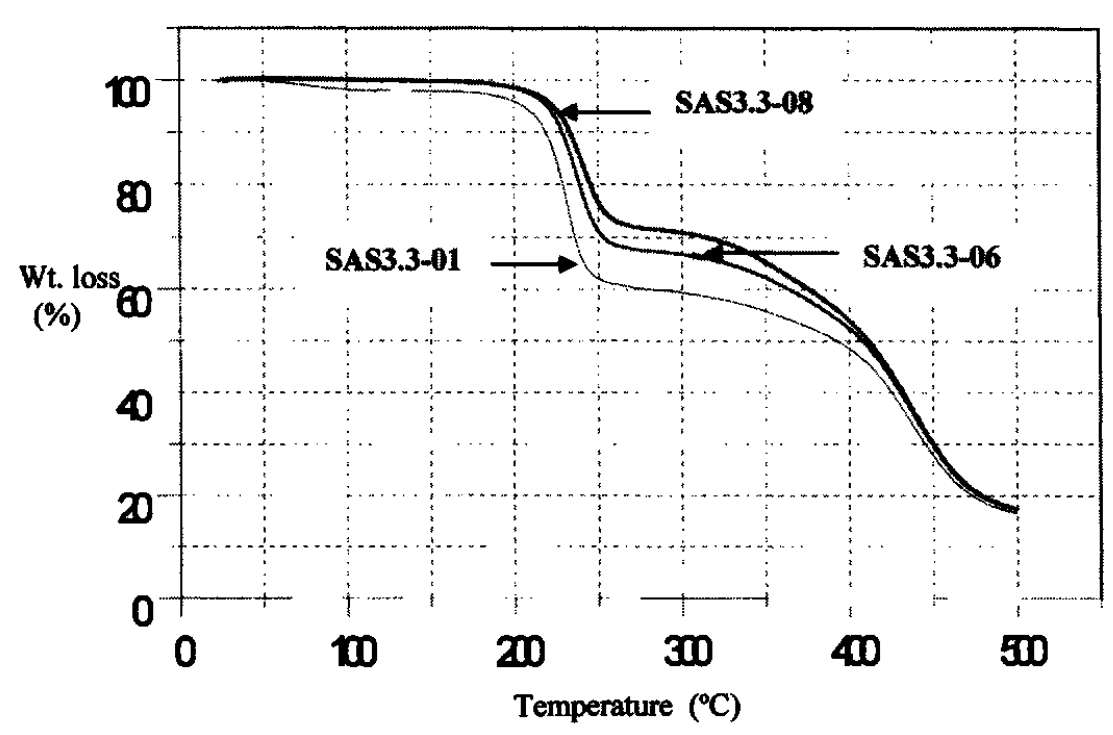

\begin{tabular}{c|c}
\hline Polymer & $\begin{array}{c}\text { Calculated weight } \\
\text { loss }(\%)\end{array}$ \\
\hline SAS3.3-01 & 41.2 \\
\hline SAS3.3-06 & 33.8 \\
\hline SAS3.3-08 & 28.7 \\
\hline
\end{tabular}

(A)

Figure 4. (A) TGA thermograms of poly(EALCNC-MA-PLNC) and (B) calculated wt. loss of EALC group in the polymers

\subsection{Etch resistance}

The dry etch resistance of the resists is a major factor in designing resists for ArF lithography. So the highly robust polymers composed of alicyclic main chains and alicyclic pendant groups were designed and prepared. Usually under conventional poly silicon etch conditions, the etch rates of some $\mathrm{ArF}$ resists were similar to that of Novolac resin. But under oxide etch conditions, most ArF resists are weaker than DUV resists. So we performed oxide etch experiments to confirm the feasibility of the polymers in device fabrication. Figure 8 shows the Ohnishi parameters and etch rate ratios of the some commercial resists and our new resists under oxide etch condition. The etch rate ratios of the new resists were 1.07-1.15 times that of DUV resist. SEM images of $L / S$ patterns obtained before after etching under oxide etch condition were shown in Figure 9. While $3000 \AA$ of the PTEOS (plasma enhanced-tetraethylorthosilicate) layer and $300 \AA$ of AR-20 were etched, about 600 $\AA$ of the resist was eroded. The etch condition is not optimized yet. If the condition is optimized, better pattern profiles can be obtained after etch.

\section{Conclusions}

A series of cycloolefin-maleic anhydride based polymers such as poly(EALCNC-MA), poly (MALCNC-MA) and poly(EALNC-MA-PTLNC) were synthesized for $193 \mathrm{~nm}$ resist applications.
(A)

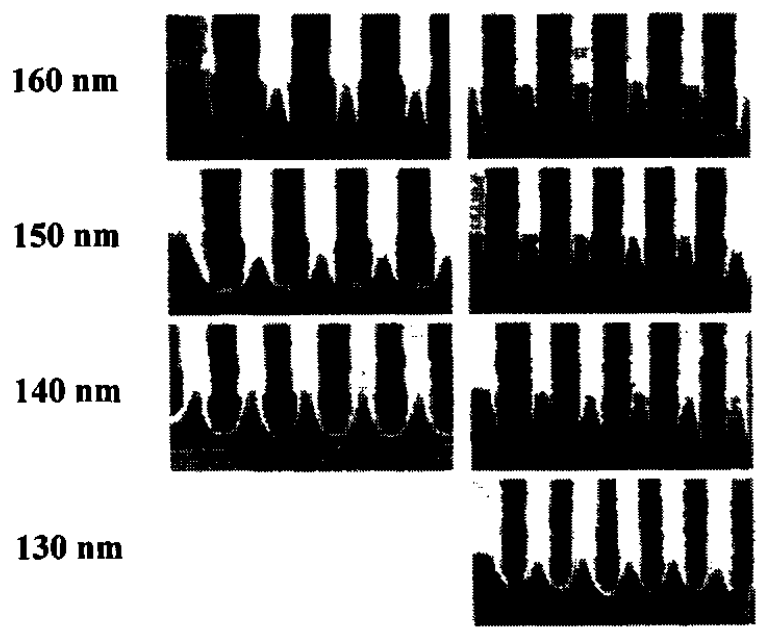

Figure 5. SEM images of $\mathrm{L} / \mathrm{S}$ patterns of (A) poly(EALCNC-MA) (B) poly(MALCNC-MA) using an ArF exposure system (ISI, NA=0.6) with conventional illumination ( Film thickness $=3500 \AA$ )

These polymers were prepared by free radical polymerization method. They showed an etch rate in $\mathrm{CF}_{4}$ mixture plasma of approximate 1.0 times that of DUV resists, and had good transparency at $193 \mathrm{~nm}$. Using an ArF exposure tool (NA=0.6, $\sigma=0.7), 130 \mathrm{~nm} \mathrm{~L} / \mathrm{S}$ patterns were resolved. Using Off-Axis illumination, $100 \mathrm{~nm} \mathrm{~L} / \mathrm{S}$ patterns were 


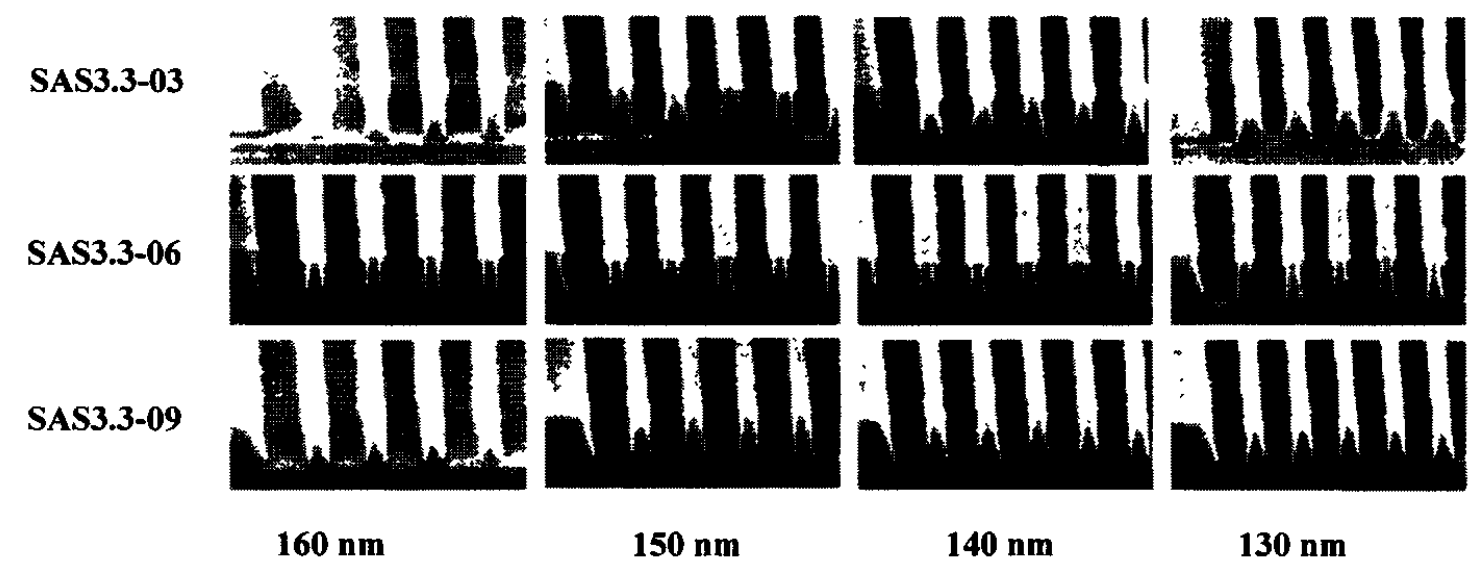

Figure 6. SEM images of L/S patterns of SAS 3.3 series using an ArF exposure system (ISI, NA=0.6) with conventional illumination (S/B: $130^{\circ} \mathrm{C} / 90 \mathrm{sec}, \mathrm{PEB}: 120^{\circ} \mathrm{C} / 90 \mathrm{sec}$ )

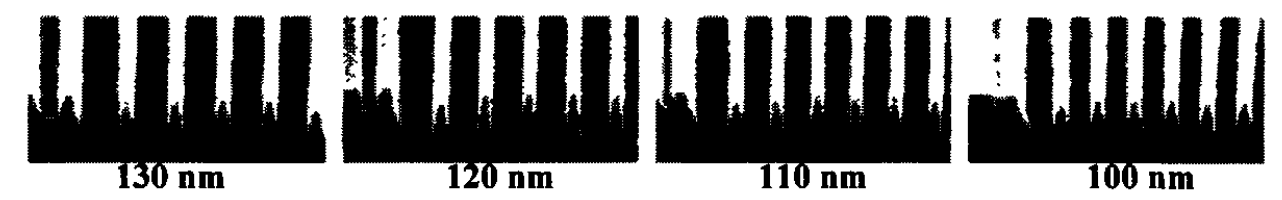

Figure 7. SEM images of L/S patterns of SAS3.3-09 using an ArF exposure system (ISI, $\mathrm{NA}=0.6$ ) with off-axis illumination

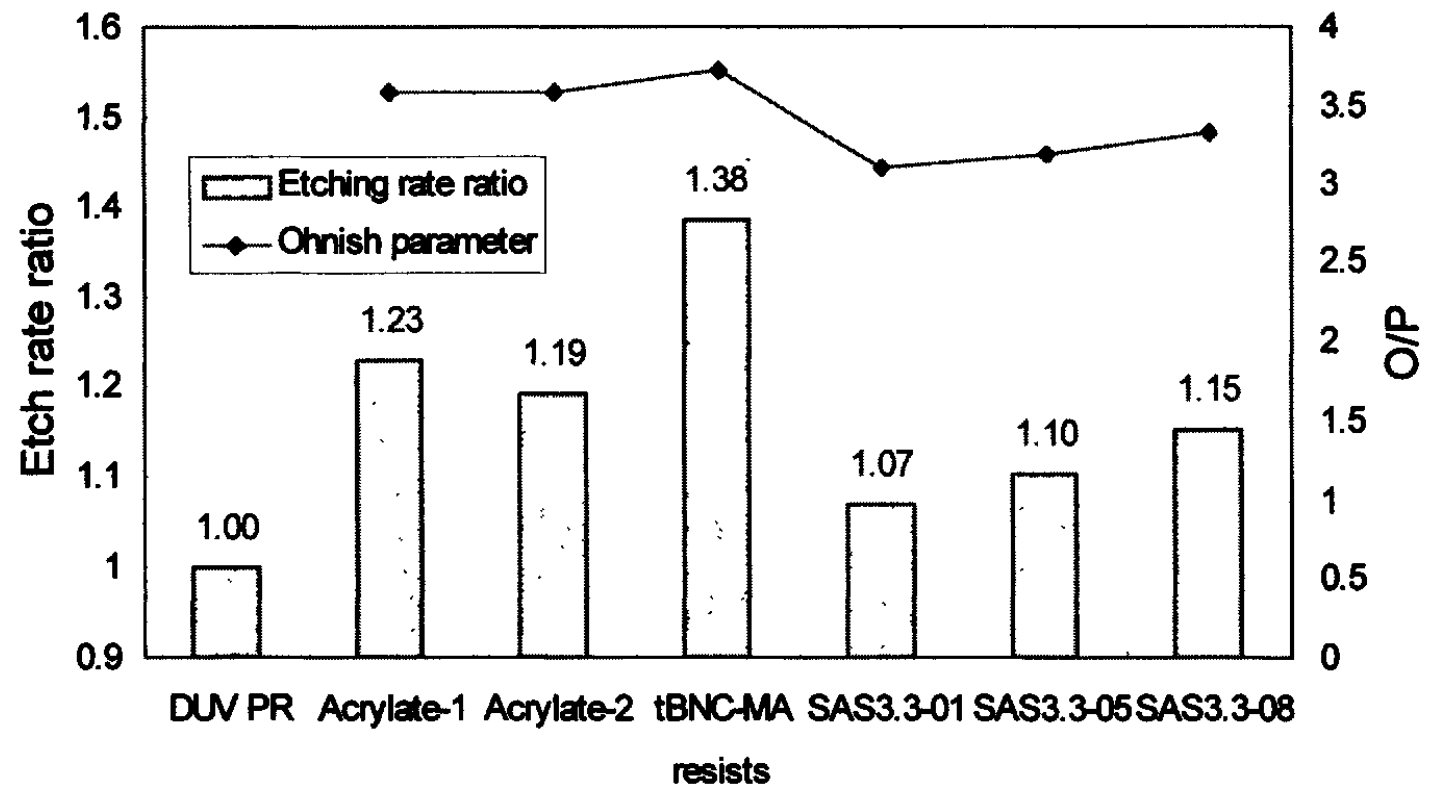

Figure 8. Etch rate ratios of the resists under oxide etch condition

resolved. It is expected that the new COMA systems can be a promising candidate for printing sub-130 $\mathrm{nm}$ devices.

\section{References}

1. U. Okoroanyanwu, T. Shimokawa, J. Byers and C. G. Willson, Chem. Mater., 10, 3319, (1998).

2. U. Okoroanyanwu, T. Shimokawa, D. Medeiros, C. G. Willson, J. Byers, Q.J. Niu, J. 
(A)

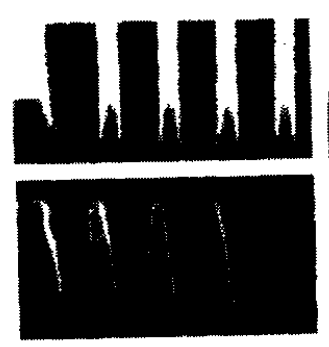

$160 \mathrm{~nm}$

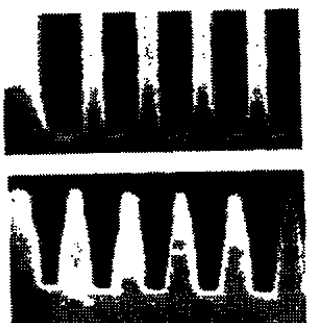

$150 \mathrm{~nm}$

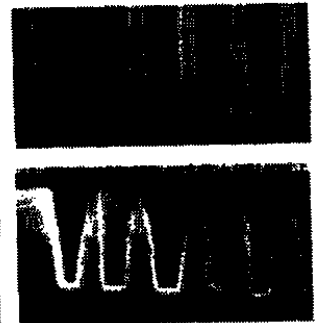

$140 \mathrm{~nm}$

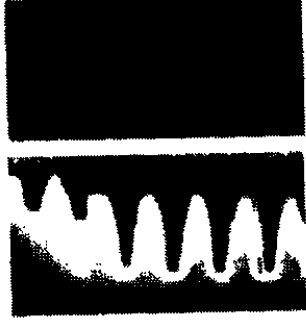

$130 \mathrm{~nm}$

Figure 9. SEM images of L/S patterns of SAS3.3-04 (A) before etch and (B) after etch

M. J. Frechet and R. D. Allen, Proc. SPIE. 3049, 272 (1997).

3. K. Nozaki and E. Yano, J. Photopolym. Sci.Technol 10, 545, (1997).

4. R. D. Allen, I. Y. Wan, G. M. Wallraff, R. A. Dipetro, D. Hofer and R.R. Kunz, J. Photopolym. Sci.Technol. 8, 623, (1995).

5. T. Tanaka, M. Morigami, and N. Atoda, Jpn. J.
Appl. Phys. 32, 6059, (1993).

6. K. Deguchi, K. Miyoshi, T. Ishii, and T. Matsuda, Jpn. J. Appl. Phys. 31, 2954,(1992).

7. S. J. Choi, Y. Kang, D. W. Jung, C. G. Park, J. T. Moon, Proc. SPIE, 3049, 104 (1997).

8. S. J. Choi, Y. Kang, D. W. Jung, C. G. Park, J. T. Moon, M. Y. Lee, J. Photopolym. Sci. Technol., 10, 521 (1997). 